\title{
A generic approach for studying the kinetics of liquid-liquid phase separation under near-native conditions
}

\author{
Joris van Lindt ${ }^{\mathrm{a}, \mathrm{b}, \#}$, Anna Bratek-Skickia,b,\#, Donya Pakravan ${ }^{\mathrm{c}, \mathrm{d}}$, Ludo Van Den Bosch ${ }^{\mathrm{c}, \mathrm{d}}$, \\ Dominique Maes ${ }^{\mathrm{b}}$, Peter Tompa ${ }^{\mathrm{a}, \mathrm{b}, \mathrm{e}^{*}}$
}

${ }^{\#}$ Joris van Lindt and Anna Bratek-Skicki contributed equally to the presented work.

*Corresponding authors:

peter.tompa@vub.be

anna.bratek-skicki@vub.be

${ }^{a}$ VIB-VUB Center for Structural Biology, Vlaams Instituut voor Biotechnologie, Brussels, Belgium.

bStructural Biology Brussels, Vrije Universiteit Brussel, Brussels, Belgium.

${ }^{c}$ VIB, Center for Brain \& Disease Research, Laboratory of Neurobiology, Leuven, Belgium

${ }^{\mathrm{d}} \mathrm{KU}$ Leuven, Department of Neurosciences, Experimental Neurology, Leuven, Belgium

eInstitute of Enzymology, Research Centre for Natural Sciences of the Hungarian Academy of Sciences, Budapest, Hungary. 
Understanding the kinetics and underlying physicochemical forces of liquid-liquid phase separation (LLPS) is of paramount importance in cell biology, requiring reproducible methods for the analysis of often severely aggregation-prone proteins. Frequently applied approaches, such as dilution of the protein from an urea-containing solution or cleavage of its fused solubility tag, however, often lead to very different kinetic behaviors. Here we suggest that at extreme $\mathrm{pH}$ values even proteins such as the low-complexity domain (LCD) of hnRNPA2, TDP-43, and NUP-98 can be kept in solution, and then their LLPS can be induced by a jump to native $\mathrm{pH}$, resulting in a system that can be easily controlled. This approach represents a generic method for studying LLPS under near native conditions, providing a platform for studying the phase-separation behavior of diverse proteins.

Compartmentalization is a basic device of eukaryotic cells for the regulation and spatiotemporal separation of their biochemical reactions. Many compartments termed organelles are surrounded by a membrane which physically separates them from the bulk cytoplasm. Cells, however, also contain many so-called "membraneless organelles" (MOs), which lack a physical barrier. MOs are involved in many cellular activities including metabolic processes and signaling pathways. Many studies suggest that liquid-liquid phase separation (LLPS) is responsible for the creation of these supramolecular assemblies. ${ }^{1-3}$ Recently, intense research has been focused on the influence of a prominent MO, stress granule, on cell survival and its link to neurogenerative diseases, such as amyotrophic lateral sclerosis (ALS). ${ }^{4,5}$ Stress granule proteins form liquid droplets, then slowly undergo gelation and, in the end, are converted into aggregated fibrils. TDP 43, FUS and heterogeneous nuclear ribonucleoprotein A2/B1 (hnRNPA2/B1) are prime examples of phase-separating stress granule proteins. Similar transformation, from solution to characteristic "FG particles", was also observed for the nuclear pore complex (NPC) protein NUP 98, which plays an important role in the bidirectional transport across the NPC. ${ }^{6}$ Due to its prevalence in a broad range of physiological and pathological processes of the cell, understanding the biophysical principles that govern LLPS is a central goal in current cell biology research.

Studies devoted to the phase separation phenomenon are dominated by the visualization of mature liquid droplets by a wide range of techniques, at a stage considered to correspond to equilibrium. Phase-separated droplets, however, are never in thermodynamic equilibrium but are in a transition towards a final state of two separate phases. Moreover, the proteins involved in these processes are aggregation prone and have a tendency to be sticky; thus, most often they are prepared either with a fused solubility tag (MBP, GFP, or GST), ${ }^{7,8}$ or under denaturing (6$8 \mathrm{M} \mathrm{urea})^{9}$ or otherwise non-physiological (very high salt, detergents) ${ }^{10}$ conditions, which may strongly interfere with experimental results. For example, transitions of the prion-like domain of Sup35 have been studied under two different conditions, starting from highly denaturing conditions $(8 \mathrm{M} \mathrm{GuHCl})$ or from a stock of very high salt; ${ }^{10}$ from initial denaturing conditions, it aggregated into amyloid-like fibers, ${ }^{11}$ whereas when diluted from high salt, it phase separated into liquid droplets which later turned into gel condensates. ${ }^{12}$ It is, therefore, obvious that LLPS is very sensitive to experimental conditions which may lead to very different conclusions in terms of preferred trajectory along the transition path: solution $\rightarrow$ droplet $\rightarrow$ gel $\rightarrow$ amorphous or amyloid aggregate. In accord, the literature is full of qualitative statements about whether a protein phase separates under given conditions, without quantitative data on the underlying kinetics and parameters that significantly influence this phenomenon. Due to the general biological importance of the phenomenon of LLPS, the field requires clear experimental standards for developing physiologically relevant models based on reproducible results. ${ }^{10,13}$ 
Toward this goal, we propose here a generic method in which phase separation is induced by a simple $\mathrm{pH}$ jump at near-native conditions. To demonstrate the benefits of our approach, we compared the kinetics of LLPS of the low-complexity domain (LCD) of hnRNPA2 initiated by a $\mathrm{pH}$ drop (from 11.0 to 7.5 ) with kinetics performed in the presence of salt, urea and by cleaving its MBP solubility tag as reported in literature ${ }^{9}$. We show that different conditions have a profound effect on kinetics of LLPS, which may lead to misinterpretation of obtained results. We also demonstrate that this principle provide a generic approach for studying the LLPS of practically any other aggregation-prone protein. By studying its $\mathrm{pH}$-dependent net charge profile, an appropriate $\mathrm{pH}$ at which the protein stays in solution can be selected, and its LLPS studied, as demonstrated through the example of two other disordered proteins: the LCD of TDP 43 and a fragment of NUP98 (Fig1S, Supporting Information).

First, we registered absorbance changes at $600 \mathrm{~nm}$ (A600) of hnRNPA2 LCD solution after $\mathrm{pH}$ dropped from 11.0 (10 mM CAPS) to 7.5 (Fig. 1a, orange line). The turbidity of the solution increased rapidly reaching maximum value within minutes, which is attributed to the formation of droplets accompanying phase separation. To confirm the phase separation, we spun down solutions at $\mathrm{pH} 11.0$ and 7.5 and using gel electrophoresis, we analyzed their supernatant and pellet. At pH 11.0 there was no pellet and the protein was present in the supernatant (Fig. 1a). However, at $\mathrm{pH} 7.5$, the supernatant was almost protein-free while in the pellet most of the protein was detected, confirming that the protein was mostly present in the condensed form. An increase of ionic strength by $150 \mathrm{mM} \mathrm{NaCl}$ (Fig. 1a, blue line) slowed down the kinetics, indicating the importance of electrostatics in LLPS.

LLPS was also demonstrated by following the evolution of the droplets in time by dynamic light scattering (DLS) (Fig. 1b). Initially, small droplets of a diameter of about $1 \mu \mathrm{m}$ were formed, growing slowly to a maximum of $3.0 \mu \mathrm{m}$ in diameter after approximately 2 hours (Fig. 1 , re line). During the increasing stage, the droplet radius increased in time with an exponential dependence of $1 / 3(t \sim 1 / 3)$, as expected for particle growth by Ostwald ripening. ${ }^{14}$ By about five hours after initiating phase separation, DLS measurements could no longer be interpreted, probably due to aggregation characterized by a high polydispersity. DLS also confirmed the importance of electrostatics, as in $150 \mathrm{mM} \mathrm{NaCl}$ it showed a significant decrease in droplet size, with a maximal value of $800 \mathrm{~nm}$ after 6 hours (Fig. 1., blue line). The evolution of droplets was also monitored by fluorescence microscopy (Fig. 1c). As DLS data suggests, small droplets were formed at the beginning of the experiment and grew over time. After 3 hours, approximately, large droplets were observed together with aggregates proving that the LLPS of hnRNPA2 LCD is not an equilibrium system.

The advantage of this approach for studying the kinetics of early stages of phase separation follows from that upon $\mathrm{pH}$ jump, there is no residual denaturant in the system (unlike upon dilution from $8 \mathrm{M}$ urea, for example), and it can be administered instantaneously by the addition of a small volume of concentrated buffer (unlike with the slow cleavage of the solubility tag). To demonstrate that these generally applied approaches can lead to potentially erroneous and artefactual results, we first initiated phase separation by diluting hnRNPA2 LCD stored in $8 \mathrm{M}$ urea into $20 \mathrm{mM}$ HEPES, $\mathrm{pH} 7.4$ buffer, resulting in a final urea concentration of $150 \mathrm{mM}$. The increase of turbidity is much slower, reaching maximum after 1.0 hour, then slowly decreasing over time (Fig. 1d, blue line). DLS data for the sample with urea confirmed the presence of particles (droplets) whose size at the beginning of the experiment was approximately $400 \mathrm{~nm}$, then slowly increased reaching ca. $800 \mathrm{~nm}$ after 6 hours (Fig. 1e, orange line). Unlike with the pH-jump system, a fit of the curve at low salt gives an exponent of 0.1798 , which is inconsistent with the process of Ostwald ripening. As an additional discrepancy, when we added $150 \mathrm{mM}$ urea to the hnRNPA2 LCD sample kept at $\mathrm{pH} 11.0$, and initiated phase separation by the $\mathrm{pH}$ 
jump to 7.5, we observed the same turbidity and DLS kinetics as without urea (Fig.1d, orange line and Fig. 1e, blue line), suggesting that urea at a high concentration, strongly interacts with protein, influencing its path of LLPS.

When LLPS was induced by a pH jump in the presence of $150 \mathrm{mM}$ urea and $200 \mathrm{mM} \mathrm{NaCl}$, kinetics again followed a path observed by the $\mathrm{pH}$ change in the absence of salt (Fig. 1d, orange line vs Fig. 1a, orange line). DLS measurements also confirmed that the size evolution of the droplets was the same as observed by the $\mathrm{pH}$ jump method (Fig. 1e, blue line vs Fig. 1b, orange line). Previous research on protein-urea interactions have shown that urea is able to solvate protein backbone and sidechains, explaining urea denaturation, ${ }^{15}, 16$ which may be prevented by strong salt-urea interactions. ${ }^{17-19}$ The effect of residual urea in the presence of $200 \mathrm{mM} \mathrm{NaCl}$ was also demonstrated by fluorescence microscopy (Fig. 1f). We observed large droplets after diluting protein-urea sample in the presence of $200 \mathrm{mM} \mathrm{NaCl}$ while no droplets were observed without $\mathrm{NaCl}$ probably due to their small size as was confirmed by DLS.

We also demonstrated adverse effects on LLPS kinetics of hnRNPA2 LCD by cleaving the MBP solubility tag with TEV protease. A striking difference from the $\mathrm{pH}$ jump was observed, as at the given protease concentration, turbidity of the solution did not significantly change for a period of 6 hours, reaching an average value of 0.15 (Fig. 1g). The DLS data showed that the size of the droplets also remained constant having an average diameter of $5.0 \mu \mathrm{m}$ without any indication of further transition(s) (Fig. 1h), i.e., the system apparently failed to demonstrate a behavior typical of LLPS. Therefore, we started a detailed analysis of the cleavage process. First, we ran aliquots of the phase separating solution taken at different times on SDS PAGE to follow cleavage of hnRNPA2 LCD-MBP. Interestingly, the cleavage was always incomplete, reaching plateau after a few hours (Fig. 1i). We hypothesized two explanations: i) either TEV got sequestered in the LLPS droplets, or ii) the hnRNPA2 LCD tail of hnRNPA2 LCD MBP was recruited in the LLPS droplet, protecting it from the cleavage. To prove our hypothesis, we spun down the droplets and analyzed the supernatant and the pellet via gel electrophoresis. We found, as expected, that most of hnRNPA2 LCD was present in the droplets (Fig. 1i). However, the most unexpected finding was the presence of TEV, the hnRNPA2 LCD MBP and the MBP tag in the droplets. Thus, in contrast to previous experiments, droplet content was very heterogenous. Therefore, experiments in which phase separation is induced by cleaving a soluble tag should be carefully analyzed.

These results have all shown that the $\mathrm{pH}$ jump system in the case of hnRNPA2 LCD enables to dissect its kinetics of LLPS under near-native conditions. Next, we sought to demonstrate that this approach can be applied to other proteins, by observing kinetics of LLPS of TDP-43 LCD and a fragment of NUP98 (Fig. 2). First, we have analyzed the net charge-pH curve of the two proteins, to select an appropriate $\mathrm{pH}$ where the proteins may not aggregate (Fig. 2a). We selected $\mathrm{pH}=3.5$ for both TDP-43 LCD and NUP-98 LCD. As appears, both proteins are in solution at the respective $\mathrm{pH}$ selected, and readily undergo LLPS when their $\mathrm{pH}$ changes to 7.5 and 10.0 for TDP 43 LCD and NUP 98 LCD, respectively. Phase separation was confirmed by turbidity assays (Fig. 2b, Fig. 2e), DLS measurements (Fig. 2c, Fig. 2f), which provided an exponent of $1 / 3$ indicative of Ostwald ripening, and fluorescent microscopy (Fig. 2d), which showed the development of $\mu \mathrm{m}$-sized droplets.

In conclusion, we present a method that can be used for studying the kinetics of early stages of LLPS of aggregation-prone proteins. By selecting an appropriate $\mathrm{pH}$, the protein can be kept in solution and its phase separation can be initiated by a change of its $\mathrm{pH}$. As the $\mathrm{pH}$ jump requires the addition of a small amount of concentrated buffer only, the composition of the system is free to vary and can be accurately controlled, thus providing a generic approach that 
is devoid of artefacts arising from the presence of residual denaturant and/or the slow and incomplete cleavage of a solubility tag.

\section{References}

1. Boeynaems, S.; Alberti, S.; Fawzi, N. L.; Mittag, T.; Polymenidou, M.; Rousseau, F.; Schymkowitz, J.; Shorter, J.; Wolozin, B.; Van Den Bosch, L.; Tompa, P.; Fuxreiter, M., Protein Phase Separation: A New Phase in Cell Biology. Trends Cell Biol 2018, 28 (6), 420-435.

2. Courchaine, E. M.; Lu, A.; Neugebauer, K. M., Droplet organelles? EMBO J 2016, 35 (15), 1603-12.

3. Banani, S. F.; Lee, H. O.; Hyman, A. A.; Rosen, M. K., Biomolecular condensates: organizers of cellular biochemistry. Nat Rev Mol Cell Biol 2017, 18 (5), 285-298.

4. Murakami, T.; Qamar, S.; Lin, J. Q.; Schierle, G. S.; Rees, E.; Miyashita, A.; Costa, A. R.; Dodd, R. B.; Chan, F. T.; Michel, C. H.; Kronenberg-Versteeg, D.; Li, Y.; Yang, S. P.; Wakutani, Y.; Meadows, W.; Ferry, R. R.; Dong, L.; Tartaglia, G. G.; Favrin, G.; Lin, W. L.; Dickson, D. W.; Zhen, M.; Ron, D.; Schmitt-Ulms, G.; Fraser, P. E.; Shneider, N. A.; Holt, C.; Vendruscolo, M.; Kaminski, C. F.; St George-Hyslop, P., ALS/FTD MutationInduced Phase Transition of FUS Liquid Droplets and Reversible Hydrogels into Irreversible Hydrogels Impairs RNP Granule Function. Neuron 2015, 88 (4), 678-90.

5. Li, Y. R.; King, O. D.; Shorter, J.; Gitler, A. D., Stress granules as crucibles of ALS pathogenesis. J Cell Biol 2013, 201 (3), 361-72.

6. Schmidt, H. B.; Görlich, D., Nup98 FG domains from diverse species spontaneously phase-separate into particles with nuclear pore-like permselectivity. Elife 2015, 4.

7. Lin, Y.; Protter, D. S.; Rosen, M. K.; Parker, R., Formation and Maturation of PhaseSeparated Liquid Droplets by RNA-Binding Proteins. Mol Cell 2015, 60 (2), 208-19.

8. Maharana, S.; Wang, J.; Papadopoulos, D. K.; Richter, D.; Pozniakovsky, A.; Poser, I.; Bickle, M.; Rizk, S.; Guillén-Boixet, J.; Franzmann, T. M.; Jahnel, M.; Marrone, L.; Chang, Y. T.; Sterneckert, J.; Tomancak, P.; Hyman, A. A.; Alberti, S., RNA buffers the phase separation behavior of prion-like RNA binding proteins. Science 2018, 360 (6391), 918 921.

9. Ryan, V. H.; Dignon, G. L.; Zerze, G. H.; Chabata, C. V.; Silva, R.; Conicella, A. E.; Amaya, J.; Burke, K. A.; Mittal, J.; Fawzi, N. L., Mechanistic View of hnRNPA2 LowComplexity Domain Structure, Interactions, and Phase Separation Altered by Mutation and Arginine Methylation. Mol Cell 2018, 69 (3), 465-479.e7.

10. Alberti, S.; Saha, S.; Woodruff, J. B.; Franzmann, T. M.; Wang, J.; Hyman, A. A. A user's Guide for Phase Separation Assays with Purified Proteins 2018, p. 4806-4820.

11. Scheibel, T.; Lindquist, S. L., The role of conformational flexibility in prion propagation and maintenance for Sup35p. Nat Struct Biol 2001, 8 (11), 958-62.

12. Franzmann, T. M.; Jahnel, M.; Pozniakovsky, A.; Mahamid, J.; Holehouse, A. S.; Nüske, E.; Richter, D.; Baumeister, W.; Grill, S. W.; Pappu, R. V.; Hyman, A. A.; Alberti, 
S., Phase separation of a yeast prion protein promotes cellular fitness. Science 2018, 359 (6371).

13. Alberti, S.; Gladfelter, A.; Mittag, T., Considerations and Challenges in Studying Liquid-Liquid Phase Separation and Biomolecular Condensates. Cell 2019, 176 (3), 419-434.

14. Feldmann, G., Fabrim, Z.E., Henning, G.L.,, Ostwald ripening of precipitates and self similarity of size distributions in reaction controlled growth. J. Mater. Sci., : 2008; Vol. 43, pp 614-620.

15. Hua, L.; Zhou, R.; Thirumalai, D.; Berne, B. J., Urea denaturation by stronger dispersion interactions with proteins than water implies a 2-stage unfolding. Proc Natl Acad Sci U S A 2008, 105 (44), 16928-33.

16. Son, I.; Shek, Y. L.; Tikhomirova, A.; Baltasar, E. H.; Chalikian, T. V., Interactions of urea with native and unfolded proteins: a volumetric study. J Phys Chem B 2014, 118 (47), 13554-63.

17. Steinke, N.; Genina, A.; Lorenz, C. D.; McLain, S. E., Salt Interactions in Solution Prevent Direct Association of Urea with a Peptide Backbone. J Phys Chem B 2017, 121 (8), 1866-1876.

18. Li, W.; Zhou, R.; Mu, Y., Salting effects on protein components in aqueous $\mathrm{NaCl}$ and urea solutions: toward understanding of urea-induced protein denaturation. J Phys Chem B 2012, $116(4), 1446-51$.

19. Muzammil, S.; Kumar, Y.; Tayyab, S., Anion-induced stabilization of human serum albumin prevents the formation of intermediate during urea denaturation. Proteins 2000, 40 (1), 29-38.

\section{Acknowledgements}

This work was supported by the Odysseus grant G.0029.12 from Research Foundation Flanders (FWO), a VUB Spearhead grant (SRP51, 2019-24) and grant K124670 from the Hungarian Scientific Research Fund (OTKA).

\section{Author Contributions}

J.V.L, P.T., L.V.D.B, and A.B.S. conceived experiments and analyzed data. J.V.L, and A.B.S. carried out experiments, D.P. performed microscopy measurements. D.M. contributed to the initial design of the experiments. A.B.S. and P.T. wrote the manuscript and all authors were involved in revising it critically for important intellectual content.

\section{Declaration of Interests}

The authors declare that they have no competing interests. 


\section{Materials and Methods}

\section{hnRNPA2 LCD expression and purification}

N-terminally polyhistidine-tagged hnRNPA2 LCD gene (R190 - Y341; UniProt P22626), located on a prokaryotic expression vector plasmid pJ411 with a kanamycin resistance gene as a selectable marker, with the lacI gene, and preceded by lac operon was a gift from Prof. Dr. N. Fawzy.

E. coli BL21 STAR (for protein expression), or NEB5 $\alpha$ (for plasmid purification) were heat transformed in LB medium at $42^{\circ} \mathrm{C}$. After 30 minutes at $37^{\circ} \mathrm{C}$, kanamycin was added, and the solution was incubated overnight and shaken at $180 \mathrm{rpm}$. From this solution, a single colony of $E$. coli cells were obtained by spreading on agar plates with kanamycin, from which a glycerol stock was prepared and stored at $-80^{\circ} \mathrm{C}$.

Precultures were prepared by dipping a sterile toothpick in the glycerol stock and incubating it in $50 \mathrm{ml} \mathrm{LB}$ with kanamycin. After overnight incubation, the precultures were added to $1 \mathrm{~L}$ of terrific broth medium and incubated until they reached OD of 0.6 to 0.8 at $37^{\circ} \mathrm{C}$ and $170 \mathrm{rpm}$. $1 \mathrm{mM}$ Isopropyl $\beta$-D-1-thiogalactopyranoside was added to induce hnRNPA2 LCD expression, and the temperature was lowered to $26^{\circ} \mathrm{C}$. After overnight incubation, cells were harvested by centrifugation at $4^{\circ} \mathrm{C}, 5000 \mathrm{rpm}$ for 20 minutes. The cells were flash frozen and stored at $80^{\circ} \mathrm{C}$.

The cells were thawed and resuspended in lysis buffer: $20 \mathrm{mM}$ Tris-Cl, $500 \mathrm{mM} \mathrm{NaCl}, 10 \mathrm{mM}$ imidazole, $1 \mathrm{mM}$ dithiothreitol supplemented with $0.1 \mathrm{mM}$ phenylmethylsulfonyl fluoride (PMSF), $0.5 \mathrm{mM}$ benzamidine hydrochloride (BA), and 1 tablet Roche complete EDTA-free protease inhibitor per $50 \mathrm{ml}$. The cells were lysed by sonication (on a Sonics VCX-70 Vibra cell) for 15 minutes ( 5 seconds pulse on, 5 seconds pulse off, $70 \%$ amplification) on ice to avoid heating the sample. Inclusion bodies, containing hnRNPA2 LCD, were pelleted by centrifugation at $24000 \mathrm{xg}$ for $1 \mathrm{~h}$ at $4^{\circ} \mathrm{C}$. The pellet was resolubilized in a denaturing buffer: $20 \mathrm{mM}$ Tris-Cl, $500 \mathrm{mM} \mathrm{NaCl}, 10 \mathrm{mM}$ imidazole, $1 \mathrm{mM}$ DTT, $3 \mathrm{M}$ urea, $\mathrm{pH} 8.0$ and centrifuged for $1 \mathrm{~h}$ at $24000 \mathrm{x}$ g and $4^{\circ} \mathrm{C}$ to pellet bacterial debris. The supernatant was filtered through a filter of $0.45 \mu \mathrm{m}$ and loaded onto a nickel-charged IMAC column (HistrapTM HP GE Healthcare), to which the polyhistidine tag of hnRNPA2 LCD binds. Bacterial debris was washed away with a denaturing buffer, after which the bound hnRNPA2 LCD was eluted with a linear $0 \mathrm{mM}$ to $250 \mathrm{mM}$ imidazole gradient.

The eluted hnRNPA2 LCD with polyHis tag was cleaved by polyHis-tagged TEV protease in a buffer of $50 \mathrm{mM} \mathrm{NaH}{ }_{2} \mathrm{PO}_{3}, 20 \mathrm{mM} \mathrm{NaCl}, 3 \mathrm{M}$ urea, $\mathrm{pH} 7.0$ at room temperature. After overnight incubation, the cleaved tag and the protease were removed by running the solution over a nickel-charged IMAC column, collecting the flow-through containing the cleaved protein.

Purified hnRNPA2 LCD was extensively dialyzed: $2 \times 4$ h, once overnight in a 0.01 M CAPS buffer, $\mathrm{pH} 11.0$ applied at a 1:100 concentration ratio. The protein was stored at a final concentration of $20 \mu \mathrm{M}$ at $-80^{\circ} \mathrm{C}$. Protein concentration was determined by densitometry of Coomassie-stained SDS-PAGE gels, and by QUBIT ${ }^{\circledR}$. 


\section{TDP 43 LCD expression and purification}

$60 \mu 1$ of $E$. coli BL21 STAR cells were transfected with 1 ul of TDP43 LCD plasmid and incubated overnight $(16 \mathrm{~h})$ in $50 \mathrm{ml} \mathrm{LB}$ medium with $50 \mu \mathrm{l}$ of LB medium with $50 \mathrm{ul}$ of kanamycin $(100 \mathrm{mg} / \mathrm{ml})$ at $37^{\circ} \mathrm{C}$. Next, $8 \mathrm{ml}$ of the cells grown overnight were injected to $1 \mathrm{~L}$ of NZYM containing $1 \mathrm{ml}$ of kanamycin and incubated at $37^{\circ} \mathrm{C}$ with continuous shaking at 170 $\mathrm{rpm}$. After, approximately, $3 \mathrm{~h}$ when the OD was higher than $0.6,500 \mathrm{ul}$ of IPTG was added into the solution and the cells grew for the next 4 hours to be optimally expressed (OD $\sim 2.0$ ). The cells were harvested by centrifugation at $4^{\circ} \mathrm{C}, 5000 \mathrm{rpm}$ for 15 minutes. A pellet from each $1 \mathrm{~L}$ solution was transferred into 1 falcon for maximal protein retention in the purification procedure. The cells were immediately frozen and stored at $-80^{\circ} \mathrm{C}$.

In the next step, the cells were thawed and resuspended in lysis buffer: $500 \mathrm{mM} \mathrm{NaCl}, 20 \mathrm{mM}$ Tris $\mathrm{HCl}, 1 \mathrm{mM}$ DTT, 1 tablet Roche complete EDTA-free protease inhibitor, $0.5 \mathrm{mM} \mathrm{BA}, 0.1$ $\mathrm{mM}$ PMSF, $\mathrm{pH} 8.0$ and sonicated in ice for 15 minutes at 70\% amplitude applying 10 seconds on and 10 seconds off cycles.

Inclusion bodies were then pelleted by centrifugation at $5000 \mathrm{xg}$ for $5 \mathrm{~min}$ at $4^{\circ} \mathrm{C}$. The pellet was resolubilized in a denaturing buffer: $20 \mathrm{mM}$ tris $\mathrm{HCl}, 8 \mathrm{M}$ urea, $500 \mathrm{mM} \mathrm{NaCl}, 10 \mathrm{mM}$ imidazole, 1mM DTT, pH 8.0 and sonicated in ice for 5 minutes or until the solution was clear as water (usually it was cycles of 5 seconds on and 5 seconds off at $70 \%$ amplitude). The solution was centrifuge at $20000 \mathrm{x}$ g for $45 \mathrm{~min}$ at $4^{\circ} \mathrm{C}$. The supernatant was filtered through a filter of $0.45 \mu \mathrm{m}$ and loaded onto a nickel-charged IMAC column (HistrapTM HP - GE Healthcare), to which the polyhistidine tag of TDP 43 LCD binds. Bacterial debris was washed away with a denaturing buffer after which the bound TDP 43 LCD was eluted with a linear 0 $\mathrm{mM}$ to $500 \mathrm{mM}$ imidazole gradient. The protein fractions were combined, $\mathrm{pH}$ was adjusted to 7.0 and the following reagents were added: 1 tablet protease inhibitor, $0.1 \mathrm{mM} \mathrm{PMSF}$, and 0.5 $\mathrm{mM}$ of BA.

Next, the solution was portioned in $1 \mathrm{ml}$ eppendorfs with $1 / 10$ of TEV protease. All samples were incubated overnight at $34^{\circ} \mathrm{C}$ without shaking.

The protein samples were combined again, and the solution was loaded onto a HiPrep 26/10 desalting column using a $20 \mathrm{mM}$ MES buffer, $\mathrm{pH}$ 5.5. The protein was filtered with $0.22 \mu \mathrm{m}$ stored at a final concentration of $55 \mu \mathrm{M}$ at $-80^{\circ} \mathrm{C}$. The effectiveness of each purification step was determined by gel electrophoresis with Page Blue staining. Protein concentration was determined by a QUBIT® kit.

\section{NUP 98 expression and purification}

The plasmid of Nup98 was provided by Addgene and expressed in E. coli BL21 cells. Protein in inclusion bodies was extracted and solubilized in a buffer of $8 \mathrm{M}$ urea, $100 \mathrm{mM} \mathrm{Na} 2 \mathrm{HPO}_{4}$, $10 \mathrm{mM}$ DTT and $10 \mathrm{mM}$ Tris-HCl, $\mathrm{pH}$ 8.5, purified through Ni-NTA affinity chromatography. The eluted protein was finally dialyzed into a PBS buffer $\mathrm{pH} 3.0$ and kept frozen at $-20^{\circ} \mathrm{C}$ in small aliquots.

\section{hnRNPA2 LCD MBP expression and purification}

E. coli BL21 STAR were heat transformed in LB medium at $37^{\circ} \mathrm{C}$. After 30 minutes at $37^{\circ} \mathrm{C}$, kanamycin was added, and the solution was incubated overnight and shaken at $180 \mathrm{rpm}$. From this solution, a single colony of $E$. coli cells were obtained by spreading on agar plates with kanamycin, from which a glycerol stock was prepared and stored at $-80^{\circ} \mathrm{C}$. 
Precultures were prepared by dipping a sterile toothpick in the glycerol stock and incubating it in $50 \mathrm{ml} \mathrm{LB}$ with kanamycin. After overnight incubation, the precultures were added to $1 \mathrm{~L}$ of terrific broth medium and incubated until they reached $\mathrm{OD}$ of 0.6 to 0.8 at $37^{\circ} \mathrm{C}$ and $170 \mathrm{rpm}$. $1 \mathrm{mM}$ Isopropyl $\beta$-D-1-thiogalactopyranoside was added to induce hnRNPA2 LCD MBP expression, and the temperature was lowered to $28^{\circ} \mathrm{C}$. After incubating overnight, the cells were harvested by centrifugation at $4^{\circ} \mathrm{C}, 5000 \mathrm{rpm}$ for 20 minutes. The cells were flash frozen and stored at $-80^{\circ} \mathrm{C}$.

The cells were thawed and resuspended in a lysis buffer: $100 \mathrm{mM} \mathrm{KCl}, 50 \mathrm{mM}$ Tris-Cl, $1 \mathrm{M}$ $\mathrm{NaCl}, 10 \mathrm{mM}$ imidazole, $1 \mathrm{mM}$ dithiothreitol supplemented with $0.1 \mathrm{mM}$ PMSF, $0.5 \mathrm{mM}$ BA, and 1 tablet Roche complete EDTA-free protease inhibitor per $50 \mathrm{ml}$. The cells were lysed by sonication (on a Sonics VCX-70 Vibra cell) for 10 minutes (5 seconds pulse on, 5 seconds pulse off; $70 \%$ amplification) on ice to avoid heating the sample. Then, the solution was incubated for $30 \mathrm{~min}$ at $37^{\circ} \mathrm{C}$ with $50 \mu \mathrm{g} / \mathrm{ml}$ DNase and $20 \mathrm{mM} \mathrm{MgCl}_{2}$.

Inclusion bodies, containing hnRNPA2 LCD MBP, were pelleted by centrifugation at 24000 $\mathrm{x} \mathrm{g}$ for $1 \mathrm{~h}$ at $4^{\circ} \mathrm{C}$. The pellet was resolubilized in a denaturing buffer: $100 \mathrm{mM} \mathrm{KCl}, 50 \mathrm{mM}$ Tris- $\mathrm{HCl}, 1 \mathrm{M} \mathrm{NaCl}, 10 \mathrm{mM}$ imidazole, $1 \mathrm{mM}$ dithiothreitol supplemented with $0.1 \mathrm{mM}$ PMSF, $0.5 \mathrm{mM}$ BA, and 1 tablet Roche complete EDTA-free protease inhibitor and centrifuged for 1 $\mathrm{h}$ at $24000 \mathrm{x}$ g and $4^{\circ} \mathrm{C}$ to pellet bacterial debris. The supernatant was filtered through a filter of $0.45 \mu \mathrm{m}$ and loaded onto a HiPrep 26/10 desalting column using a $20 \mathrm{mM}$ Tris-HCl, 200 $\mathrm{mM} \mathrm{NaCl}, 1 \mathrm{mM}$ DTT, pH 7.4 buffer. Next, the protein samples were combined again, and the solution was loaded onto MBP-trap HP column and eluted with $20 \mathrm{mM}$ tris-HCl, $200 \mathrm{mM}$ $\mathrm{NaCl}, 1 \mathrm{mM}$ DTT, $10 \mathrm{mM}$ maltose, $\mathrm{pH} 7.4$ buffer.

\section{Initiating phase separation}

\section{hnRNPA2 LCD}

We observed that the hnRNPA2 LCD is relatively stable in $10 \mathrm{mM}$ CAPS buffer at $\mathrm{pH} 11.0$, but rapidly phase separates when its $\mathrm{pH}$ was decreased to 7.5. Thus, we kept the protein in aliquots in a $10 \mathrm{mM}$ CAPS at $\mathrm{pH} 11.0$ and initiated phase separation, first by diluting the protein to the appropriate concentration in the same buffer, then starting the reaction by decreasing the $\mathrm{pH}$ with $1.6 \mu \mathrm{l}$ of $0.5 \mathrm{M}$ MES pH 5.5 for every $100 \mu \mathrm{l}$ of protein solution to a final value of 7.5. However, for each batch and different protein concentrations a proper amount of MES should be carefully adapted. Phase separation commenced immediately and could be then followed and characterized by a variety of techniques.

\section{TDP $43 L C D$}

TDP 43 LCD is stable in $20 \mathrm{mM}$ MES buffer at $\mathrm{pH} 3.5$ and phase separates when $\mathrm{pH}$ increases to 7.5. Therefore, the protein was stored under these conditions and phase separation was induced by applying an appropriate volume of $0.5 \mathrm{M} \mathrm{CAPS}$ buffer, $\mathrm{pH} 11.0$ to orangeuced $\mathrm{pH}$ up to 7.5. Usually, for $200 \mu \mathrm{l}$ of TDP $43 \mathrm{LCD}(55 \mu \mathrm{M})$ we added $5 \mu \mathrm{l}$ of CAPS buffer $(0.5 \mathrm{M}$, $\mathrm{pH} 11.0)$.

\section{NUP98-LCD}

NUP 98-LCD is stable in $50 \mathrm{mM}$ PBS buffer at $\mathrm{pH} 3.5$ and phase separates when $\mathrm{pH}$ increases to 10.0. Therefore, the protein was stored under these conditions and phase separation was induced by applying an appropriate volume of 0.1 M CAPS buffer, $\mathrm{pH} 11.0$ to orangeuced $\mathrm{pH}$ up to 10.0 . 


\section{Fluorescent labelling with Dylight ${ }^{\circledR} 488$}

hnRNPA2 LCD

$100 \mu \mathrm{l}$ of of $8 \mathrm{mg} / \mathrm{ml} \mathrm{hnRNPA2} \mathrm{LCD} \mathrm{in} \mathrm{TEV} \mathrm{cleavage} \mathrm{buffer} \mathrm{(} 3 \mathrm{M}$ urea, $200 \mathrm{mM} \mathrm{NaCl}, 50$ $\mathrm{mM} \mathrm{NaH} \mathrm{PO}_{4}$ ) was dialyzed against $0.1 \mathrm{M}$ sodiumcarbonate buffer, $\mathrm{pH} 8.5 .10 \mathrm{mg} / \mathrm{ml}$ of the fluorescent Dylight ${ }^{\circledR} 488$ dye (Thermo scientific) was dissolved in DMSO and added to the protein at a final concentration of $0.05 \mathrm{mg} / \mathrm{ml}$. The solution was incubated at room temperature for $1 \mathrm{~h}$ and then was dialyzed against $0.01 \mathrm{M}$ CAPS, $\mathrm{pH} 11.0$ storage buffer, to remove the excess of unbound fluorophore. Fluorescently labelled hnRNPA2 LCD was protected from light and stored at $-80^{\circ} \mathrm{C}$.

TDP $43 L C D$

$100 \mu \mathrm{M}$ of Dylight ${ }^{\circledR} 488$ dye (Thermo scientific) was used to label TDP 43 LCD for fluorescent microscopy measurements. TDP $43 \mathrm{LCD}(55 \mu \mathrm{M})$ in 1x PBS was added to the dye and incubated at room temperature for $30 \mathrm{~min}$ in darkness. The mixture was then desalted with the Zeba ${ }^{\mathrm{TM}}$ Desalting Spincolumns, 7K MWCO (Thermo Fisher Scientific) to the reaction buffer (1x PBS, $10 \mathrm{mM} \mathrm{MgCl} 2,0.05 \%$ Tween 20). Fluorescently labelled TDP 43 LCD was protected from light and stored at $-80^{\circ} \mathrm{C}$.

\section{Turbidity measurements}

In addition to the MES buffer and/or CAPS buffer to manipulate the $\mathrm{pH}$, appropriate volumes of sodium chloride (Sigma $\left.{ }^{\circledR}\right)$ was administered to a non-binding black 96 well plate with transparent bottoms. The following protein solutions were used: i) $200 \mu \mathrm{l}$ of $20 \mu \mathrm{M}$ hnRNPA2 LCD in CAPS buffer, $\mathrm{pH} 11$ was mixed with $1.6 \mu \mathrm{l}$ of $0.5 \mathrm{M}$ MES pH 5.5 to reach a final $\mathrm{pH}$ equal to 7.5 , ii) $200 \mu \mathrm{l}$ of $55 \mu \mathrm{M}$ TDP 43 LCD in $20 \mathrm{mM}$ MES, pH 5.5 buffer was mixed with $5 \mu \mathrm{l}$ of $0.5 \mathrm{M}$ CAPS, $\mathrm{pH} 11.0$ buffer to reach a final $\mathrm{pH}$ equal to 7.0. In order to measure phase separation at different concentrations, a volume of MES or CAPS buffer should be carefully adapted. The protein solution was simultaneously added to each well containing a desired buffer, and after a short mixing, the plate was covered with a transparent film (VIEWsealTM) and the absorbance of the solution was measured at $600 \mathrm{~nm}$ for 6 hours on a BioTek SynergyTM Mx plate reader at $25^{\circ} \mathrm{C}$ with continuous shaking. Experiments were conducted in triplicate and then averaged.

\section{Dynamic light scattering measurements}

Dynamic light scattering (DLS) measurements were carried out on a DynaPro NanoStar (Wyatt) instrument. A disposable cuvette (WYATT technology) was filled with $100 \mu \mathrm{l}$ of protein solution at $\mathrm{pH}$ and concentration values at which phase separation was observed. The sides of the cuvette were filled with water and a cap was put on top. The intensity of scattered light was recorded at a scattering angle of $95^{\circ}$ at $25^{\circ} \mathrm{C}$ for a period of 6 hours collecting 10 acquisitions ( $8 \mathrm{~s} \mathrm{each).} \mathrm{Each} \mathrm{measurement} \mathrm{was} \mathrm{repeated} \mathrm{at} \mathrm{least} 3$ times. The software package DYNAMICS 7.1.9 was used to analyse the data, and particle size was calculated based on the following formulas:

$$
\begin{gathered}
G^{2}(\tau)=\langle I\rangle^{2}\left(1+\alpha e^{-2 D_{t} q^{2} \tau}\right) \\
D_{t}=\frac{k T}{6 \pi \eta R_{h}}
\end{gathered}
$$


where $G^{2}(\tau)$ is autocorrelation function, $D_{t}$ is the hydrodynamic radius, $\tau$ is delay time, $q$ is refractive index, $D_{t}$ is diffusion coefficient, $k$ is the Boltzmann's constant, $T$ is temperature, $\eta$ is viscosity of fluid, $R_{h}$ is hydrodynamic radius.

\section{Fluorescent and brightfield microscopy}

Microscopy measurements were carried out on a Leica DMi8 microscope. Dylight ${ }^{\circledR} 488$ labeled hnRNPA2 LCD or TDP 43 LCD were mixed with non-labelled hnRNPA2 LCD or TDP 43 LCD (at a 1:200 ratio). Then, phase separation was induced by changing the $\mathrm{pH}$ of the protein solution as described earlier. The solution was incubated at $25^{\circ} \mathrm{C}$ and droplets were visualized with 100 times magnification with brightfield, and/or fluorescence microscopy (FITC filter).

\section{Statistical analysis}

Statistical analysis was performed in Microsoft Office Excel. All data are shown as mean \pm standard deviation. 


\section{pH change method}

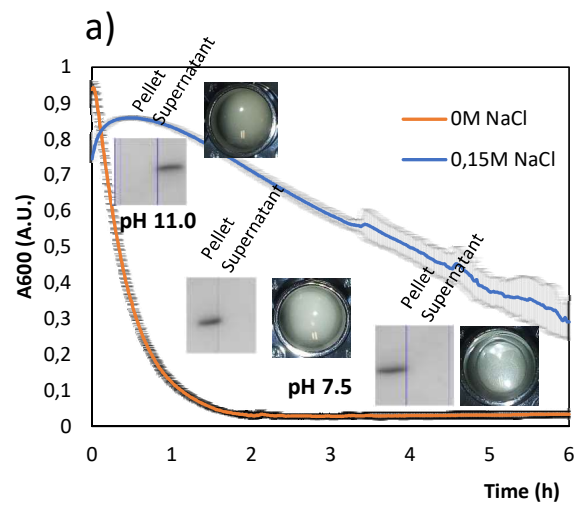

b)

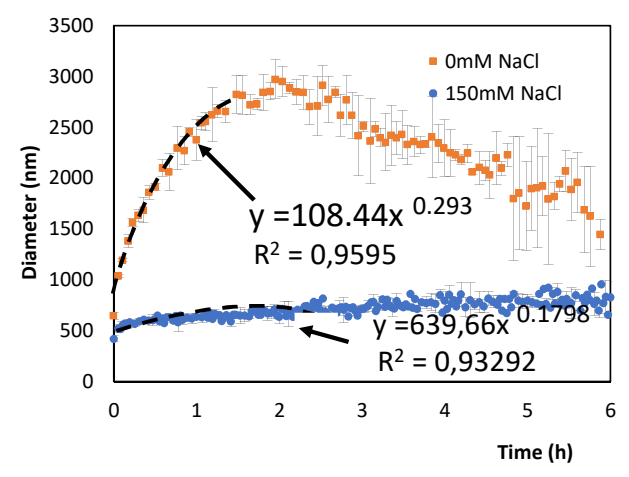

c)

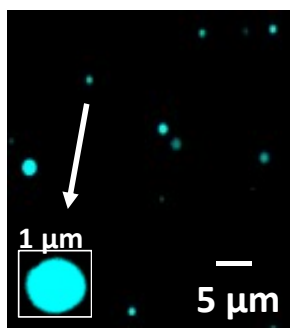

No incubation

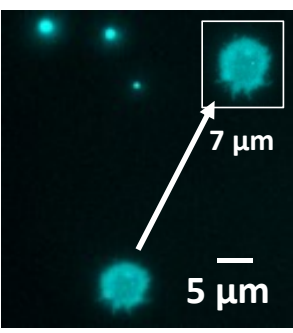

$3 \mathrm{~h}$ incubation

\section{Presence of urea}

d)

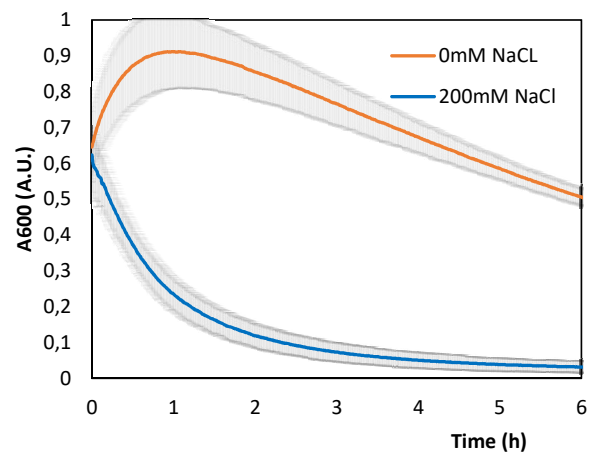

e)

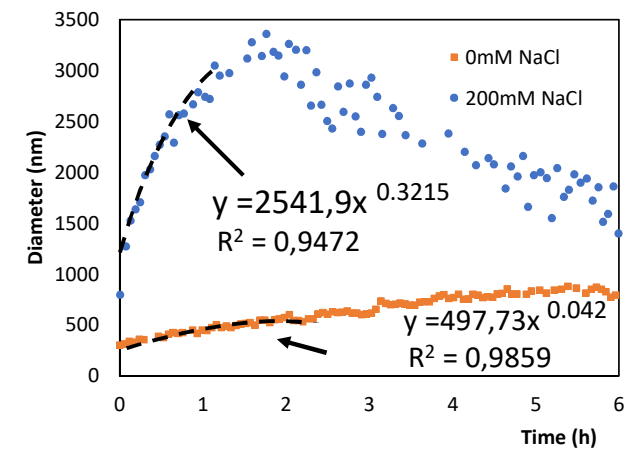

f)

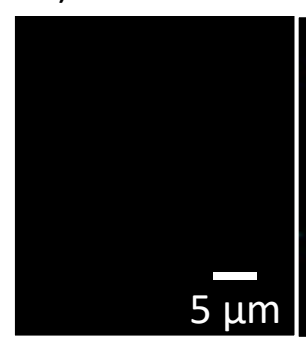

No incubation

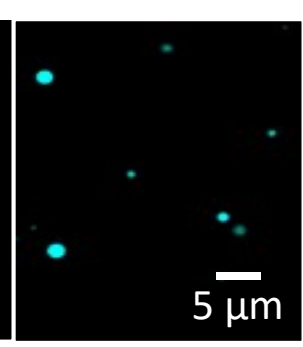

No incubation Urea, without $\mathrm{NaCl}$ Urea, $200 \mathrm{mM} \mathrm{NaCl}$

Cleaving MBP tag

g)

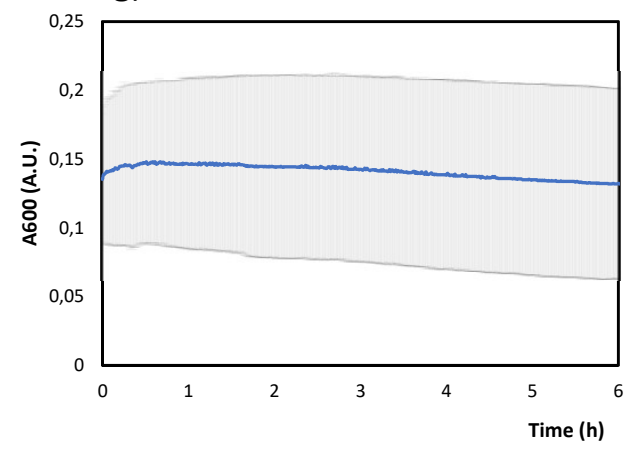

h)
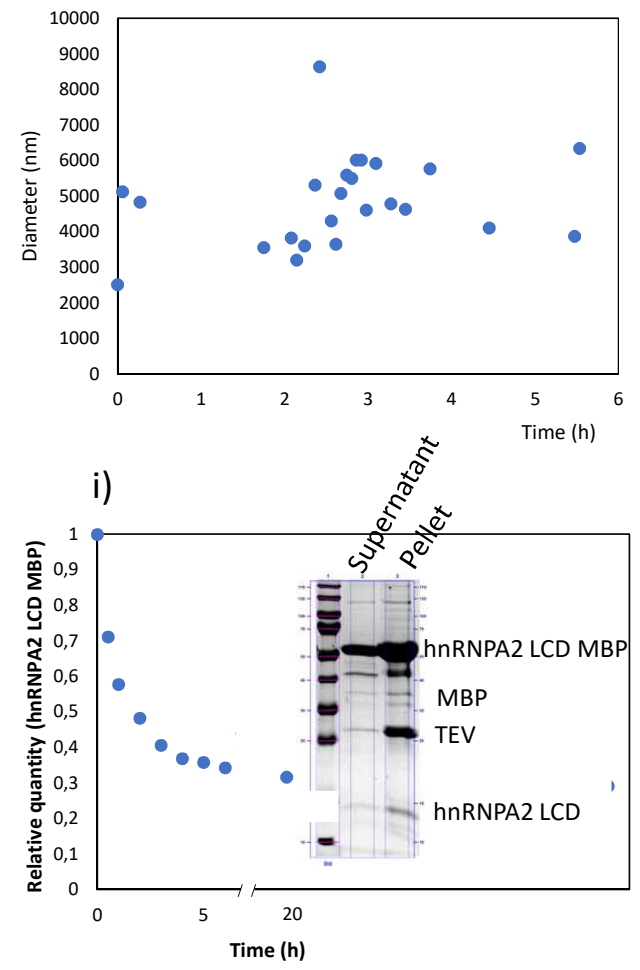

Fig.1 Phase separation (PS) of hnRNPA2 LCD initiated by three methods: i) by pH change (left side), ii) in the presence of urea (in the middle), iii) by cleaving the MBP tag (right side); a) PS of hnRNPA2 LCD monitored by turbidity without $\mathrm{NaCl}$ (orange line), with $150 \mathrm{mM} \mathrm{NaCl}$ (blue line) with inserted images of SDS PAGE gels representing the content of the supernatant and the pellet after incubation time of $1 \mathrm{~min}, 30 \mathrm{~min}$, and $1 \mathrm{~h}$, b) size evolution of droplets monitored by DLS without $\mathrm{NaCl}$ (orange line), with $150 \mathrm{mM} \mathrm{NaCl}$ (blue line) c) fluorescence microscopy images of droplets without incubation and after $2 \mathrm{~h}$ incubation, d) PS of hnRNPA2 LCD in the presence of urea monitored by turbidity without $\mathrm{NaCl}$ (orange line), with $200 \mathrm{mM} \mathrm{NaCl}$ (blue line), e) size evolution of droplets monitored by DLS without $\mathrm{NaCl}$ (orange line), with $200 \mathrm{mM} \mathrm{NaCl}$ (blue line), f) fluorescence microscopy images of droplets formed in the presence of urea (left side) and with the presence of urea and $200 \mathrm{mM} \mathrm{NaCl}$ (right side),g) PS of hnRNPA2 LCD induced by cleaving the MBP tag monitored by turbidity, h) DLS measurements of hnRNPA2 LCD droplets formed after cleaving the MBP tag, i) cleavage rate of the hnRNPA2 LCD MBP protein with inserted image of SDS PAGE gel representing the content of the supernatant and the pellet after cleaving the MBP tag. 
a)

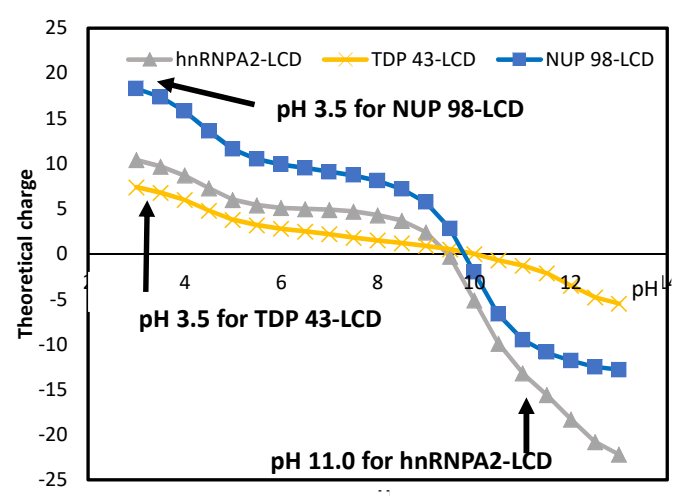

c)

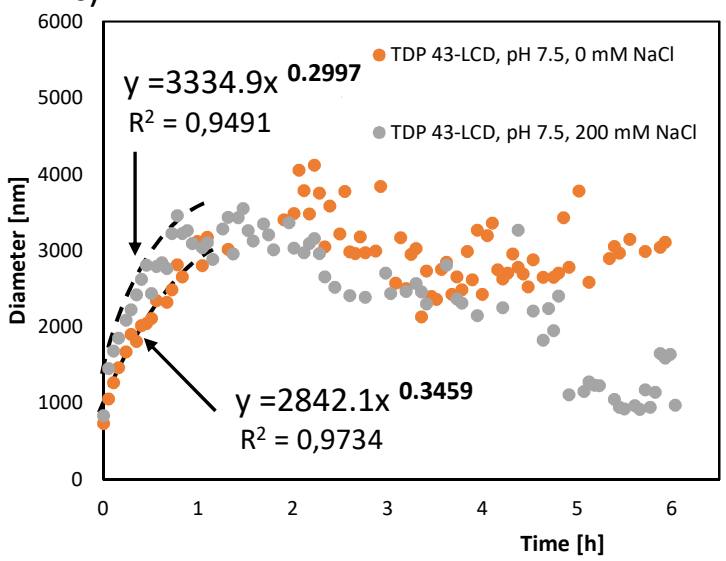

d)

No incubation

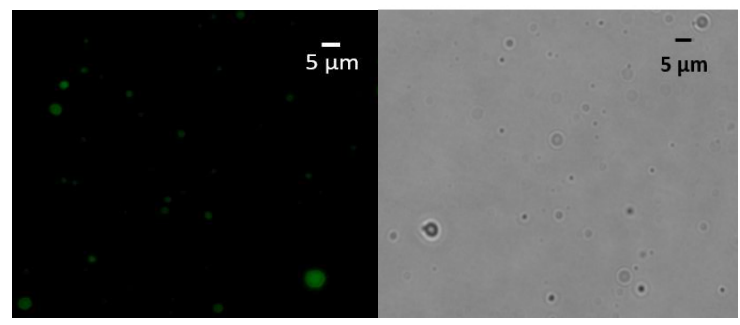

b)

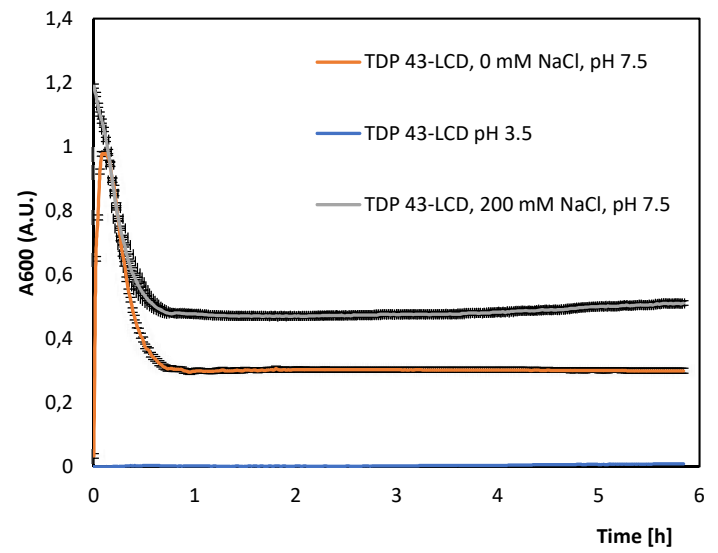

e)

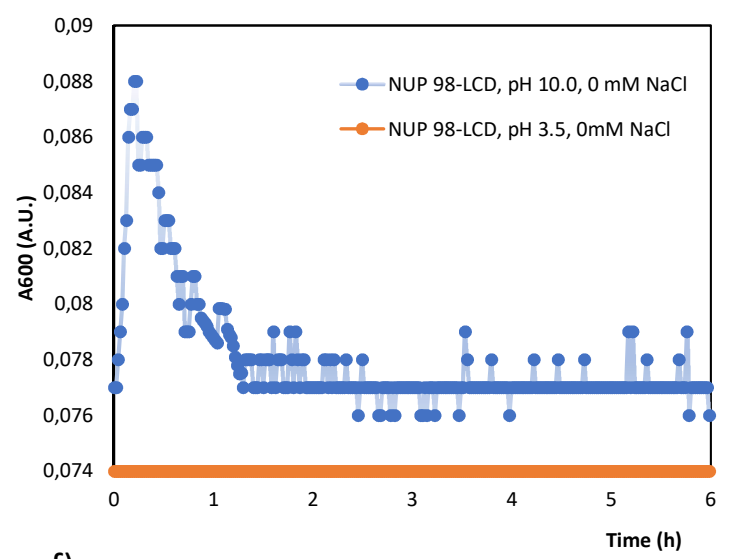

f)

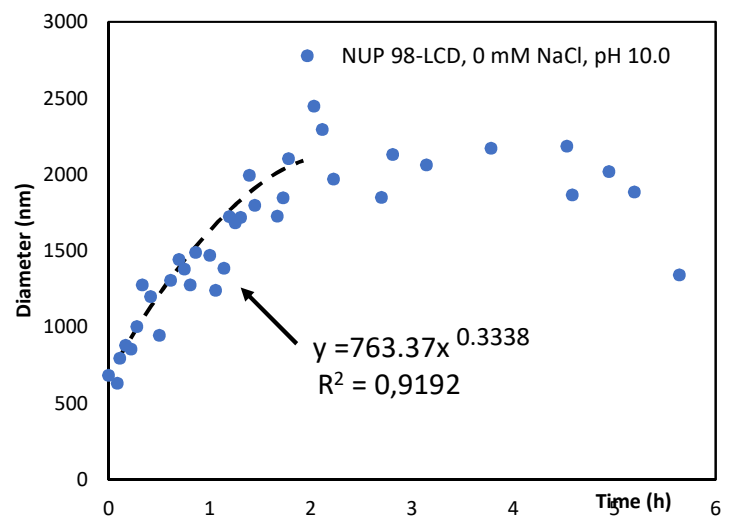

Fig.2 Phase separation of TDP 43-LCD and NUP 98-LCD: a) dependence of theoretical charge on pH of hnRNPA2-LCD (grey line), TDP 43-LCD (yellow line), NUP 98-LCD (blue line) with pH values at which proteins remain in solution, b) PS of TDP 43-LCD monitored by turbidity without $\mathrm{NaCl}$ (orange line), with $150 \mathrm{mM} \mathrm{NaCl}$ (gray line), c) size evolution of TDP 43-LCD droplets monitored by DLS without $\mathrm{NaCl}$ (orange dots), with $150 \mathrm{mM}$ $\mathrm{NaCl}$ (gray dots), d) fluorescence and bright field microscopy images of droplets of TDP 43-LCD without incubation, e) PS of NUP 98-LCD monitored by turbidity without $\mathrm{NaCl}$ (blue dots), f) size evolution of NUP 98LCD droplets monitored by DLS without $\mathrm{NaCl}$ (blue dots). 